\title{
EL TURISMO RURAL EN ESPAÑA: TERMINOLOGÍA Y PROBLEMAS DE TRADUCCIÓN ${ }^{1}$ \\ Adrián Fuentes Luque \\ Universidad Pablo Olavide \\ Grupo de Investigación AVANTI \\ afuentes@upo.es
}

\section{ABSTRACT}

This article intends to provide an introductory overview of the diverse range of terminology in the rural tourism sector and particularly the different types of lodging in different countries, emphasising the rich variety of designations and potential problems that such nomenclatures may raise in the promotion and development of tourism at national and international level.

KEYWORDS: terminology, rural tourism, tourist accommodation.

\section{RESUMEN}

En este artículo pretendemos ofrecer una visión introductoria de la diversa terminología presente en el sector del turismo rural, y más concretamente en lo referente a los diversos tipos de alojamientos, poniendo énfasis en la gran variedad de denominaciones y en los potenciales problemas que dichas nomenclaturas pueden suponer en la promoción y desarrollo turísticos a nivel nacional e internacional.

PALABRAS CLAVE: terminología, turismo rural, alojamiento turístico.

\section{INTRODUCCIÓN}

Las primeras experiencias de turismo rural datan de mediados del siglo XX y se sitúan en países europeos como Irlanda, Reino Unido, Austria y Francia. En España, este tipo de turismo comienza tímidamente en los años sesenta, pero no es hasta la década de los ochenta cuando el turismo rural se desarrolla de una forma más generalizada, particularmente en el norte de la

\footnotetext{
${ }^{1}$ Quiero agradecer la información proporcionada por M. Gutiérrez Molina para la realización de este artículo.
} 
Península Ibérica, sobre todo en las comunidades de Asturias, País Vasco y Navarra. Son especialmente destacables las iniciativas llevadas a cabo tanto en el País Vasco con el agroturismo como en Navarra con las casas rurales, iniciativas que se extendieron con posterioridad al resto de España.

En este artículo pretendemos ofrecer una visión introductoria de la diversa terminología presente en el sector del turismo rural, y más concretamente en lo referente a los diversos tipos de alojamientos, poniendo énfasis en la gran variedad de denominaciones y en los potenciales problemas que dichas nomenclaturas pueden suponer en la promoción y desarrollo turísticos a nivel nacional e internacional.

\section{TURISMO RURAL: CONCEPTO Y CARACTERÍSTICAS}

El turismo rural surge como consecuencia de una revalorización de los espacios rurales, ya que estos ofrecen contacto directo con la naturaleza e interés antropológico y etnográfico. Se trata de espacios que ofrecen atractivos tales como la ausencia de contaminación y ruido, alta calidad paisajística, la cordialidad y espontaneidad de sus habitantes, la gastronomía tradicional y la tranquilidad, como alternativas al ritmo frenético de la vida urbana.

Por otra parte, este tipo de turismo se perfila como creador y dinamizador del empleo y, por tanto, contribuye al arraigo de la población rural, ya que le permite obtener fuentes de ingresos alternativas a la agricultura o la ganadería, además de potenciar las consiguientes demandas de infraestructuras y servicios.

Por las razones expuestas, las diferentes administraciones públicas españolas (central, autonómica, provincial y local) han desarrollado políticas de apoyo al turismo rural, dejando a la administración autonómica la regulación de las diferentes modalidades de alojamientos rurales, en cuestiones tales como la tipología de estos y sus características constructivas, espaciales y de equipamiento. Esta asunción de competencias en materia de turismo rural se deriva del artículo 148, 1, 18 de la Constitución Española: "Las Comunidades Autónomas podrán asumir competencias en las siguientes materias: (...) 18. Promoción y ordenación del turismo en su ámbito territorial".

Antes de abordar las diferentes tipologías de alojamientos rurales, definiremos qué se entiende por turismo rural, sirviéndonos para ello de la definición que ofrece el Instituto de Estudios Turísticos²:

Todo tipo de aprovechamiento turístico en espacio rural siempre que cumpla con las siguientes limitaciones: que se trate de

2 http://www.iet.tourspain.es/paginas/home.aspx?idioma=es-ES [fecha de consulta: mayo de 2007]. 
un turismo difuso (es decir, oferta dispersa y no concentrada), que sea respetuoso con el patrimonio natural y cultural, que implique la participación activa de la población local, que mantenga las tradiciones del medio, huyendo del gigantismo y del monocultivo turístico.

En definitiva, nos encontramos ante una modalidad de turismo peculiar que se caracteriza fundamentalmente por la dispersión de la oferta, a la que se le añaden ciertos valores ecológicos, medioambientales, antropológicos y étnicos, como alternativa diferenciadora al turismo de sol y playa, masificado y hoy por hoy sobreexplotado.

Asimismo debemos resaltar su condición de fuente generadora de riqueza, gracias a la cual se obtienen ingresos cuantificables económicamente a la vez que se mejoran las condiciones de vida de las familias del sector agropecuario. Además, esta modalidad turística pone de relieve el intercambio intercultural entre el turista y la población local, función que incluso se contempla en algunas leyes de turismo, como la Ley del Turismo de Andalucía de 15 de diciembre de 1999, que propugna el fomento del turismo como instrumento de comunicación y conocimiento entre los pueblos, y como medio de desarrollo de los valores propios de la cultura andaluza.

A partir de la definición del Instituto de Estudios Turísticos, podemos identificar las siguientes características del turismo rural. En primer lugar, es un tipo de aprovechamiento turístico que se desarrolla en el espacio rural. En segundo lugar, es un turismo innovador, ya que se trata de una actividad no tradicional que aporta posibilidades de riqueza y desarrollo al medio rural. Por otra parte, es un turismo disperso, sin grandes concentraciones ni infraestructuras, que se debe integrar en su entorno sin dañarlo. Como tercera característica, señalamos que es una forma de turismo que posibilita la comunicación e intercambio entre el turista y la población local, por lo que ésta desempeña un rol muy importante. Además, el turismo rural es una forma de promoción y salvaguarda de valores y tradiciones socioculturales que forman parte de la vida diaria de la población rural, tales como la gastronomía, las fiestas populares, la artesanía, etc. Todo ello constituye un factor de interés para el visitante.

Por último, debe tenerse en cuenta que si el turismo rural posibilita la comunicación y el conocimiento entre los diferentes pueblos, habrá que analizar las distintas culturas que conforman la demanda de esta modalidad turística, a fin de conocer sus motivaciones, sus características, sus lenguas, etc., de modo que la oferta satisfaga las expectativas del turista y, en consecuencia, se promueva la continuidad de la demanda.

La oferta de turismo rural debe obedecer, consecuentemente, a todas las características señaladas. No obstante, también podemos identificar una 
serie de problemas que afectan a este tipo de turismo. El primero de ellos sería la gran dispersión existente con respecto a las modalidades de alojamientos rurales en España. Para solventar este problema, es necesario uniformar conceptualmente, en la medida de lo posible, las diferentes clases de alojamientos rurales que se ofertan en cada comunidad autónoma, ya que existen denominaciones iguales para tipos diferentes y denominaciones diferentes para productos similares. La homogeneización de la oferta es fundamental para que el potencial cliente, tanto nacional como extranjero, sepa qué va a encontrar en cada región. Sirva como ejemplo la enumeración de la diferente oferta de alojamientos existente en las comunidades autónomas de España, con sus múltiples modalidades 3 :

- Andalucía: existen las casas rurales, los hoteles rurales, las casas-cueva, los apartamentos turísticos, los complejos turísticos rurales, albergues, aulas de la naturaleza, casa forestal, casa molino, chozas, casas de huerta, cortijo, granja-escuela, hacienda, refugio, y alojamientos especiales.

- Aragón: se distinguen las viviendas de turismo rural de alojamiento compartido, viviendas de turismo rural de alojamiento no compartido, apartamentos de turismo rural, casas de turismo rural, albergues y refugios.

- Asturias: casonas, casas aldeas, hoteles, albergues y campings.

- Baleares: la oferta de alojamiento está configurada por agroturismo, turismo de interior, hoteles rurales y otra oferta complementaria.

- Canarias: casas rurales y hoteles rurales.

- Cantabria: palacios y casonas cántabras, posadas de Cantabria, casas de labranza, viviendas rurales y albergues turísticos.

- Castilla-La Mancha: casas rurales de alojamiento compartido, casas rurales de alquiler y casas de labranza.

- Castilla y León: posadas, centros de turismo rural, casa rural de alojamiento compartido y casas rurales de alquiler.

- Cataluña: masías, casas de pueblo y alojamientos rurales independientes.

- Extremadura: apartamentos turísticos, hotel rural, casas rurales, hospederías y agroturismo.

3 http://www.planrural.com/propietarios/legislacion_turismo_rural.htm [fecha de consulta: enero de 2009]. 
- Galicia: aldeas de turismo rural, pazos, castillos, monasterios, casas grandes y casas rectorales, casas de aldea y casas de labranza.

- Comunidad de Madrid: hotel rural, casa rural, apartamentos de turismo rural, alojamientos de turismo rural.

- Región de Murcia: hospedería rural, casa rural de alquiler, casa rural en régimen compartido, casa-torre, alquería, casa almazara, casa molino, casa huerto, casa palacio, alojamientos turísticos especiales en zonas de interior.

- Navarra: casas rurales de vivienda y casas rurales de habitación.

- La Rioja: casas rurales, posadas.

- Comunidad Valenciana: alojamiento en casas rurales compartidas, acampada en finca particular con vivienda habitada y albergues turísticos de uso colectivo.

- País Vasco: alojamiento turístico agrícola, apartamentos turísticos, viviendas turísticas vacacionales, alojamiento en habitaciones de viviendas particulares, establecimientos de alojamiento turístico en el medio rural, agroturismo, casas rurales, hoteles rurales, campings rurales y apartamentos rurales.

El segundo de los problemas que puede identificarse al estudiar el turismo rural en España es la escasa oferta de ocio, que complementaría la estancia de los visitantes, haciendo que fuese más prolongada, y la inexistencia de materiales promocionales adecuados y orientados al turista que fomenten dichas oferta.

Por otra parte, en algunas zonas geográficas existen muchas deficiencias tanto de infraestructuras (carreteras, transportes, señalización turística, etc.) como de servicios. Estas carencias deterioran la imagen de la zona y disminuyen la calidad de la oferta.

Otro hecho constatable es el escaso control que ejercen las Administraciones Públicas sobre el crecimiento de la oferta, aun cuando dichas administraciones realizan esfuerzos para incentivar el turismo rural a través de subvenciones. A pesar de estas iniciativas, no se controla ni el número de empresas situadas en el medio rural, ni los requisitos de determinados alojamientos que se ofrecen como tales, cuyas instalaciones distan mucho de encuadrarse en este tipo de oferta. La legislación sobre turismo rural no es homogénea, ya que existe una normativa por cada comunidad autónoma. Además, hay comunidades autónomas en las que apenas se supervisan estos alojamientos por falta de inspectores.

Por último, la gran asignatura pendiente del turismo rural en España es la formación de los prestadores de servicios turísticos rurales, a fin de que 
adapten tales servicios a las necesidades de la demanda y conozcan las finalidades y objetivos del turismo rural. Tanto los propietarios como el personal de estas empresas carecen, por lo general, de formación y cualificación, a diferencia de otras empresas turísticas, donde los empleados son profesionales cualificados (informáticos, titulados universitarios en turismo, traductores, guías...) con amplios conocimientos sobre atención al cliente, idiomas, recursos turísticos, nuevas tecnologías, gestión de reservas, etc. Por lo tanto, si se quiere prestar un servicio de calidad, tendrá que ser por medio de profesionales cualificados, con lo que se deberá invertir en formación.

En definitiva, la oferta española en turismo rural, a pesar de ser rica y variada en recursos medioambientales, gastronómicos y arquitectónicos, es pobre en los demás recursos, sobre todo en los de alojamiento y oferta complementaria.

\section{LA OFERTA DE TURISMO RURAL EN LOS PAÍSES EUROPEOS}

En este apartado, examinaremos la oferta de los países pioneros en el nacimiento del turismo rural. Por su proximidad, Francia se toma como referencia para las iniciativas de turismo rural españolas. Los denominados Gîtes ruraux — regulados por la Federación Nacional de Alojamientos Gîtes de France desde 1955- constituyen la principal modalidad de alojamiento de turismo rural en Francia. Se trata de casas rurales cuyos servicios, equipamientos y modalidades constructivas, en función de la categoría asignada (de una a cinco espigas o Epis), están totalmente normalizados y homogeneizados, y son objeto de controles de calidad periódicos. Estas modalidades de alojamiento están especializadas en diferentes tipos de usuarios; así, encontramos chambres d'hotel, Gîtes d'enfants (especializadas en niños), le gîte d'etape et de sejour (modalidad de grupo y de paso), le chalet-loisir (que posibilitan la práctica, en la naturaleza, de actividades como pesca, equitación, cicloturismo, tiro con arco, etc.), le camping à la ferme (posibilidad de instalar tiendas de campaña y caravanas en granjas o sus proximidades) y les sejours thematiques (alojamientos situados en lugares específicos como parques nacionales, zonas de nieve, viñedos...).

Aparte de la tipología anteriormente descrita, existe la modalidad denominada Logis de France, conformada por establecimientos hoteleros de pequeño y mediano tamaño, clasificados por tipos, que ofrecen una buena relación calidad-precio y cuidan esmeradamente la tradición gastronómica.

Portugal es otro país vecino que posee oferta en turismo rural (incluso aparece ésta junto con la española en determinadas guías informativas). La promoción de su turismo rural va dirigida principalmente a mercados exteriores 
(británicos, alemanes y franceses), principales demandantes de la oferta existente en el país.

No obstante, Portugal no distingue tantas tipologías de alojamientos como España (lo que induce al desconcierto y provoca la excesiva diversidad de características de cada modalidad de alojamiento rural). Así, en Portugal existen sólo cinco clases de alojamientos rurales: alojamientos de turismo rural, casas de campo, turismo de aldea (turismo de aldeia) (casas rústicas en zonas rurales), agroturismo (integrado en una explotación agrícola) y turismo de babitaçao (alojamiento de gran calidad y tradición, formado por casas solariegas).

Como Portugal, Irlanda es un país con tradición en turismo rural y una oferta orientada hacia mercados exteriores. Destacan las mansiones rurales irlandesas (Country Mansions), situadas en lugares de gran belleza paisajística, con muchas comodidades, cocina de alto nivel y oferta complementaria de ocio (pesca, equitación y cursos de cocina). También pueden encontrarse granjas (boliday farms), además de hoteles, campings, pensiones, aldeas de vacaciones (boliday cottages) y casas privadas (country and town house).

El Reino Unido, país europeo pionero en turismo rural, posee una amplia oferta de alojamientos de esta modalidad en todo su territorio. En primer lugar, tenemos las casas de huéspedes (guesthouses), con servicios de alojamiento y desayuno, divididas en categorías según su calidad (excepcional, de primera clase, excelente, muy bueno, bueno, razonable o aceptable). También encontramos los famosos y extendidos Bed \& Beaksfast (BひB), con posibilidad de alojamiento y desayuno, además de las cottages, casas de campo que se alquilan enteras, las farms o granjas, y alojamientos más modestos como las cabins (cabañas o refugios con servicios básicos, a menudo sin electricidad).

\section{LOS TURISTAS}

Como señalábamos anteriormente, la oferta española en turismo rural presenta considerables carencias en lo relativo a la calidad de los alojamientos y a la oferta complementaria. Por esta razón, es vital realizar un profundo análisis de la demanda de turismo rural, relacionada fundamentalmente con el tipo de visitante: nacionalidad, nivel económico, servicios complementarios que demanda, destinos preferidos, tradición y antigüedad de la oferta de turismo rural en los países de origen y forma en que el turista ha tenido conocimiento de la oferta, incluyendo la publicidad de la misma.

Con carácter general, se puede afirmar que el tipo de turista que hace uso de la oferta de turismo rural en España suele ser fundamentalmente nacional, principalmente en fines de semana, puentes, Navidad, Semana Santa y verano, produciéndose un periodo de gran estacionalidad de la oferta (en torno al $42 \%$ ) en los meses de junio, julio y agosto, (según datos publicados por el 
Instituto Nacional de Estadística) ${ }^{4}$. Los destinos favoritos del turista nacional son Castilla y León, Cataluña, Asturias, Cantabria y Galicia. La mayoría de los usuarios suelen viajar en familia y utilizan el coche como medio de locomoción principal, son respetuosos con las costumbres locales, tiene un nivel de estudios de grado medio o superior y se documenta antes de su estancia.

Frente a esto, llama poderosamente la atención que el porcentaje de visitantes o turistas extranjeros que eligieron la modalidad de turismo rural es, en comparación al de los españoles, muy inferior, ya que supone menos de un $10 \%$ del total. Estos turistas extranjeros proceden en su mayoría de otros países de la Unión Europea, fundamentalmente Reino Unido y Alemania, que se consolidan como los principales mercados demandantes de apartamentos y alojamientos de turismo rural, seguidos de los procedentes de los Países Bajos, usuarios de campings. A estos les siguen en importancia los ciudadanos franceses.

En España, las islas Baleares es el principal mercado de turismo rural para los turistas extranjeros, seguido de Castilla y León, Andalucía y las islas Canarias. Esto se debe, por una parte, a su oferta, consistente en la unión de alojamiento (destacan las posadas reales de Castilla y León, que cuentan ya con una marca de excelencia), restauración y actividades al aire libre, y por otra parte, a la extensión y localización de su territorio.

Las comunidades autónomas como Baleares o Murcia, con áreas turísticas principalmente costeras, alcanzan una gran cantidad de pernoctaciones de turistas extranjeros en alojamientos de turismo rural. Sin embargo, en Andalucía, el turismo rural no acaba de despuntar debido a dos razones: la primera, la fuerte atracción que sigue ejerciendo en el turista extranjero (fundamentalmente ingleses y alemanes) la modalidad de turismo de sol y playa, por lo que sólo visitan el campo o una localidad de interior (con una sola pernoctación) cuando ésta posee una buena oferta monumental, cultural, histórica o paisajística; y la segunda, el llamado turismo residencial, que consiste en adquirir una segunda residencia en municipios costeros de la Costa del Sol, Cádiz, Huelva o el litoral granadino. Esto hace que las principales inversiones en promoción, publicidad y comercialización de estos destinos vayan enfocadas a la promoción del turismo de sol y playa y se priorice la promoción del turismo residencial frente a la oferta de turismo rural. Por ello, en las localidades costeras andaluzas se hace necesaria una fórmula que aúne la oferta de sol y playa con el turismo rural, como se ha conseguido en otras comunidades como Asturias, donde las excursiones a playas cercanas se han convertido en parte de la oferta complementaria y de la información que se les

${ }^{4}$ http: $/ /$ www.ine.es $/$ jaxi $/$ menu.do?type $=$ pcaxis\&path $=\% 2 \mathrm{Ft} 11 \% 2 \mathrm{Fe} 162 \mathrm{eotr} \&$ file $=$ inebase $\& \mathrm{~L}=$ 0 [fecha de consulta: enero de 2009]. 
proporciona a los usuarios de alojamientos rurales, con lo que se ha logrado captar la atención de los posibles turistas europeos.

Respecto al perfil del turista extranjero que hace uso de la oferta de turismo rural, se trata de personas que suelen planificar el viaje por su cuenta. Según los datos del Instituto de Estudios Turísticos (IET) ${ }^{5}$, dependiente del Ministerio de Industria, Turismo y Comercio de España, más del 51\% se ha informado antes de venir al destino sobre el alojamiento y la oferta complementaria, bien por medio de amigos que visitaron ese lugar, bien a través de guías especializadas (fundamentalmente las de Turespaña), folletos de agencias, Internet, anuncios en medios de comunicación, portales turísticos institucionales (como el de la web de Turespaña o la web de la empresa Turismo Andaluz), centrales de reservas o, en menor porcentaje, a través de ferias como Fitur.

Estos turistas buscan espacios abiertos en paisajes en los que no se perciba la intervención de la mano del hombre y donde sea posible contemplar especies animales y vegetales en su hábitat, así como practicar actividades lúdicas, deportivas y culturales.

El motivo de su viaje suele ser por ocio o vacacional. La edad media del turista oscila entre los 35 y 45 años, aunque cada vez más se está incorporando los mayores de 55 años. Viajan en parejas, con niños o en grupos de amigos. Y en cuanto al gasto medio diario, hay que señalar que el de los turistas europeos es mayor al de los nacionales, ya que el primero invierte en restauración, alquiler de coches, ocio, visitas organizadas, etc.

El nivel cultural del viajero europeo es alto (formación de grado medio o universitaria) y, por lo general, suelen desempeñar trabajos relacionados con profesiones liberales, como los técnicos superiores o medios.

Aunque la opinión general del visitante europeo sobre la oferta turística es positiva, alabando las excelencias del clima, la hospitalidad y la tranquilidad, existen algunas quejas (por parte de británicos y franceses) relativas a la falta de infraestructuras y servicios (por ejemplo, la falta de limpieza, el poco cuidado con el medio ambiente o el idioma).

El turista europeo tiene una gran preocupación medioambiental e interés por el conocimiento del patrimonio histórico artístico de la región, de ahí la necesidad de proporcionarle información detallada (mediante folletos, guías, mapas, publicaciones especializadas y guías locales) en su lengua de origen. Sin embargo, la mayor parte de las guías disponibles en el mercado están editadas en español, por lo que apenas existen publicaciones en otras lenguas de la Unión Europea. Además, apenas existen publicaciones (guías, folletos, etc.) multilingües. Si a la demanda de información en destino se le une que el visitante hable una lengua diferente al prestador del servicio, se impone

\footnotetext{
${ }^{5}$ http:/ / www.iet.tourspain.es/paginas/PubFrontur.aspx?option=front\&idioma=es-ES.
} 
la necesidad de formación y cualificación profesional para los titulares de las explotaciones de turismo rural y sus empleados.

En resumen, el turista extranjero que hace uso de la oferta de turismo rural necesita recibir información sobre dicha oferta tanto con anterioridad a su viaje como una vez que llega a su destino. $Y$ esta información debe proporcionársele en su propia lengua.

En la siguiente sección, abordaremos la problemática de la traducción de la terminología relacionada con el turismo rural.

\section{LA TRADUCCIÓN DE LA TERMINOLOGÍA DEL TURISMO RURAL}

Como acabamos de señalar, el turista extranjero debe tener a su disposición la información sobre la oferta de turismo rural en su propia lengua. Sin embargo, la traducción de la terminología propia de esta modalidad turística presenta ciertos problemas (en concreto, las traducciones relacionadas con la gastronomía, la publicidad de la oferta de turismo rural y la tipología de alojamientos rurales) que examinaremos a continuación.

Un recurso influyente y demandado por el turista extranjero para la práctica del turismo rural es la variedad de la oferta gastronómica tradicional. Para satisfacer esta demanda de los turistas transnacionales, debe proporcionárseles información en sus lenguas de origen, tanto sobre los platos que conforman dicha oferta, como los ingredientes y la procedencia de estos, recetas tradicionales, venta de productos locales, etc. La obligación de proporcionar información gastronómica queda regulada en algunas legislaciones autonómicas en relación con ciertos establecimientos de restauración como, por ejemplo, los mesones rurales, a los que la normativa andaluza en el Decreto 20/2.002, de 29 de enero de Turismo en el medio rural y turismo activo (BOJA $\mathrm{n}^{\circ}$ 14, de 2 de febrero) define en los siguientes términos:

Aquellos establecimientos de restauración ubicados en el medio rural [...] que ostenten, al menos, cuatro de los siguientes criterios:

a) Que se trate de un edificio tradicional o que sin serlo se adecue a las características arquitectónicas de la comarca donde se encuentre ubicado.

b) Que la decoración, mobiliario y vajillas y demás elementos sea adecuada a los modelos tradicionales de la comarca.

c) Que la carta incorpore la gastronomía tradicional de la comarca y así se especifique.

d) Que utilice preferentemente productos locales, comarcales, o andaluces en general, en la preparación de las comidas. 
e) Que utilicen alimentos de producción integrada o agricultura ecológica.

f) Que facilite información a la persona usuaria, tanto sobre los productos y recetas como de la comarca donde se encuentre ubicado el establecimiento.

Todos estos requisitos serán de interés especial tanto si se presta información sobre la oferta gastronómica de la comarca como para la atracción del potencial turista rural. Además, si se dispone en el establecimiento de restauración de información gastronómica traducida a diferentes lenguas, junto con profesionales cualificados que hablen al menos dos idiomas, los servicios prestados ganarán en calidad. Sin embargo, la información en uno o varios idiomas no se da por igual en todos los establecimientos de restauración, pues mientras que en unos la carta está traducida (ya sea por exigencia legal o por la categoría del establecimiento), en otros, de inferior categoría o menos controlados, la carta no aparece traducida, ni siquiera al inglés.

En un estudio anterior (Fuentes, 2005: 82) se analizaba la traducción del propio término "gastronomía" al inglés en diversas campañas turísticas institucionales. En dicho estudio se llevó a cabo un pequeño estudio de recepción entre una muestra de nativos de diversos países de habla inglesa (Australia, Canadá, Irlanda, Reino Unido, Estados Unidos) de diverso trasfondo cultural, educativo y diferente edad. Algunos de los entrevistados ni siquiera conocían el significado de la palabra. A ninguno de ellos les gustaba el término, afirmando, por ejemplo, que "no me gusta esa palabra, suena horrible", "me suena a problemas gastrointestinales (como acidez de estómago, úlceras, reflujo, gases, etc.)". Otros comentarios iban en una línea más razonada: "Sé que en Europa el término se refiere a la comida de gourmet. Pero yo prefiero la palabra "cuisine". Este es uno de los casos en los que una idea publicitaria potencialmente de éxito puede fracasar si no se tiene en cuenta la participación del traductor como experto interlingüístico e intercultural en el proceso creativo.

En los casos en los que sí se dispone de una traducción del menú, esta suele ser en dos idiomas, uno de ellos el inglés. El otro será el francés o el alemán, dependiendo de la procedencia de los turistas que mayoritariamente se reciban en la zona. En todo caso, con demasiada frecuencia, no se dedica ni la atención ni el cuidado necesarios a las traducciones de menús. Así, son notables (y reales) los ejemplos que, lamentablemente, exceden lo anecdótico. Por ejemplo, en la carta de un restaurante de Torremolinos ofrecen "rape al gusto", pero el visitante anglosajón quedará estupefacto ante la traducción "rape as you like" (literalmente, "viole como quiera"). En otro restaurante, ubicado en el centro de Cádiz, es posible encontrar un exquisito "pulpo a la gallega", que en inglés se torna en un grito de guerra: "octopus to the Galician" (literalmente, "pulpo, a por el gallego"). 
Otro de los problemas que inciden negativamente en la atracción del turista internacional demandante de servicios de turismo rural es la dificultad existente para promocionar y publicitar la oferta de este tipo de turismo. Ello es debido a dos factores: el primero, la falta de canalización adecuada para las promociones, como consecuencia de la escasez de recursos a la que se enfrentan los pequeños hoteles y alojamientos rurales, gestionados normalmente por empresarios individuales o pequeñas empresas familiares; el segundo factor es la localización de las zonas donde se da este tipo de oferta turística: poblaciones con pocos habitantes cuyos ayuntamientos cuentan con bajos ingresos.

La solución definitiva a estos dos problemas pasa por que todos los sectores implicados en la oferta turística rural aúnen esfuerzos para ofrecer una información de calidad al cliente potencial. Ello sólo se conseguirá a través de la configuración de una información realizada por profesionales, con la suficiente formación y capacitación en las diferentes lenguas que conforman la demanda de turismo rural.

Cabe distinguir dos clases de información proporcionada al turista. La primera es la información que sirve para captar la atención del turista potencial; esta información debe facilitarse en la lengua del futuro visitante. La segunda es la información que se presta al turista una vez que está en el destino, para satisfacer sus expectativas y conseguir que vuelva.

La publicidad existente de la oferta de turismo rural es sufragada tanto por organismos públicos como por particulares. A menudo, se acude al asociacionismo entre los empresarios de este sector turístico para realizar la campaña de publicidad específica de un alojamiento o de la oferta complementaria.

De entre las diversas administraciones públicas que intervienen en turismo en España, es de especial mención Turespaña, dependiente del Ministerio de Industria, Turismo y Comercio, que lleva a cabo las funciones de promoción turística en el exterior. Para sus promociones, Turespaña se vale tanto de la publicación de carteles, folletos y guías en distintas lenguas, como de su Web (www.tourspain.es). Junto a Turespaña, las administraciones autonómicas como la andaluza (que, a través de la empresa pública Turismo Andaluz, y por medio de la web www.andalucia.org, ofrece amplia información sobre recursos turísticos, alojamientos, etc. en diferentes idiomas como español, inglés, francés y alemán) informan sobre destinos, rutas, alojamientos, etc.

Por otro lado, los folletos editados tanto por instituciones públicas como privadas deberán reunir una serie de características para cumplir su finalidad informativa:

1. Despertar el interés del visitante, a fin de que se decida a la elección del destino. 
2. Tener una portada atractiva que anime a leer la información.

3. Ofrecer variedad de imágenes, representativas del destino.

4. Incluir información que posibilite la venta final del producto (dirección de la empresa, teléfono, fax, mail y web).

5. Presentar información sobre las características del producto y la oferta complementaria de ocio, deportiva y cultural, así como sobre los recursos turísticos de la zona.

6. Dar un mensaje suficientemente convincente como para atraer al consumidor.

Con respecto a este último punto, será de especial importancia que el mensaje aparezca en varios idiomas. Actualmente, como mínimo, se impone el empleo del inglés, aunque, si se ofrece en más lenguas, aumentarán las posibilidades de obtener futuros clientes y de internacionalización del producto o el servicio. Pero para prestar esta información en otra lengua hay que hacer un uso correcto y adecuado de ésta, que posibilite la consecución de la finalidad deseada. Por ello, las traducciones han de ser esmeradas, sin omitir información práctica (como distancias al aeropuerto u horario de apertura de monumentos y museos) y con un resultado atractivo para el visitante.

Con la incorporación de las nuevas tecnologías a los canales de distribución y comercialización de la oferta rural, Internet se ha convertido en el medio más usado por el turista para acceder a la variada y múltiple información sobre la oferta rural. Además, Internet es el canal a través del cual se contratan, directa o indirectamente, los servicios de turismo rural, bien a través de centrales de reservas, bien mediante las webs de asociaciones de turismo rural. Por estas circunstancias, las webs de turismo rural deberán contener unos mínimos informativos:

1. En la página de inicio, se presentarán las diferentes lenguas en las que se ofrece la información. El uso del idioma inglés se hace casi obligado como idioma universal, sin olvidar el francés, alemán, portugués, holandés o sueco, dependiendo de los principales mercados de la zona de destino.

2. La web debe incluir la descripción exhaustiva del tipo de alojamiento: características constructivas de la edificación, forma de acceso, situación, antigüedad, número de habitaciones, servicios comunes y oferta complementaria, sin olvidar información práctica básica de comercio electrónico (como apunta Dahdá, 2005: 77) (formas de pago, central de reservas, etc.).

En algunas normativas turísticas, como es el caso de la andaluza, se recoge la obligación de informar al cliente sobre celebraciones de fiestas locales que alteren las condiciones pactadas durante los días de alojamiento o que 
puedan incidir en la prestación de servicios. Así, este tipo de información también se incluye en páginas web como la asturiana www.casasdealdea.com, que ofrece una relación de las festividades de la zona donde se encuentra el alojamiento.

Por lo que respecta a la traducción de la terminología relacionada con las tipologías de alojamiento, en principio, cabe señalar que la terminología turística en general presenta una serie de peculiaridades. La primera es que el turismo tiene un marcado carácter internacional que impregna todo su léxico, compuesto en su mayoría por internacionalismos de origen anglosajón, por ser el inglés el idioma del turismo, a excepción de algunos galicismos como hotel o route (camino o itinerario para un viaje).

Pero la incorporación de anglicismos no es el único rasgo que caracteriza al vocabulario turístico. Éste contiene, además, algunos términos patrimoniales de diferentes realidades y culturas locales que se han ido conservando a lo largo del tiempo y se siguen usando para nombrar las modalidades de alojamientos rurales. Así, es habitual el empleo de vocablos como hospedería, casa rectoral, pazo, masía, casona, posada, caserío, cortijo, fonda y un sinfín de términos más pertenecientes a formas de alojamientos rurales típicas del territorio español.

La dificultad surge al traducir estos arcaísmos a otras lenguas en las que no existen términos similares. Sin embargo, el problema se soluciona incorporando junto a la traducción una descripción de dichos alojamientos, con una finalidad explicativa y no divulgativa o comercial.

El segundo factor que caracteriza a las traducciones de términos de turismo rural es la frecuente pérdida u omisión de información en la traducción. Si la versión española ofrece una minuciosa descripción del alojamiento, en las traducciones a otros idiomas suele ocurrir que se omite o se pierde parte de esa información, ya que la traducción se limita a la parte informativa comercial. Con dicha omisión informativa, al turista se le ofrece una visión primordialmente comercial del alojamiento y se le priva de un conocimiento más profundo y clarificador de la oferta, restándole atractivo y calidad a ésta.

La tercera característica se refiere a la traducción de la terminología de la tipología de alojamientos turísticos. El problema estriba en encontrar en la lengua de origen del visitante un término que sea equivalente al término en español, es decir, que refleje esta tipología y sus características. Para solucionar este problema, unas veces se acude a términos y expresiones de otros idiomas que nada tienen que ver con las características del alojamiento, como es el caso de casa rural, que en algunas webs aparece mal traducida al francés como maison rurale o maisons rurales, o al inglés como rural country o country house. Estas traducciones literales, además de contener errores gramaticales, no reflejan el sentido de lo que en realidad es una casa rural, no consiguen que los futuros 
visitantes relacionen dichos términos con tipos de alojamiento semejantes en sus países de procedencia y, menos aún, que se formen una idea lo más real posible del tipo de oferta. Por tanto, la traducción deberá acompañarse de información adicional (tanto visual como descriptiva) sobre el alojamiento.

Otras veces se emplean términos que designan alojamientos rurales de otros países, pero que no reflejan la realidad tipológica del alojamiento ofertado, ni tienen relación con ésta. Sirva como ejemplo el uso de la expresión gîte rural en la traducción al francés de casa rural. En Francia, los gîtes ruraux conforman una cadena nacional homologada, controlada y con diferentes categorías, como ya se expuso. En consecuencia, si el turista proviene del país vecino, no sólo creerá estar en un alojamiento de este tipo, sino que tendrá unas expectativas relativas a precios, equipamiento, categoría y servicios complementarios que no coincidirán con los específicos de los gîtes ruraux.

Otra expresión empleada en la traducción al francés de casa rural es ferme rural ("granja rural"), que pretende designar el tipo de alojamiento situado en el medio rural, con o sin animales. Dicha traducción no puede emplearse para denominar "granjas" a todos los tipos de alojamientos situados en el campo, ya que, si de unos se predica esta cualidad, de otros no, y el hecho de contar con animales no los caracteriza forzosamente como granjas. Pero, además, el empleo de la expresión formada por la unión de los vocablos ferme y rural sólo consigue añadir más confusión a la información que se quiere dar al turista. Una granja está siempre situada en el campo y el uso del adjetivo rural induce a pensar que el tipo de alojamiento sería una modalidad específica de granja, es decir, la rural. Pero si todas las granjas están ubicadas en el medio rural y no existen especialidades de éstas, el calificativo rural junto con ferme es redundante.

Un caso similar sería la expresión appartement rural, que en ciertas traducciones del español al francés designa casas diferenciadas de la misma titularidad, que se ofertan y forman parte del mismo conjunto arquitectónico (por ejemplo, cortijos) pero no de un bloque o conjunto de bloques, como los apartamentos. Una vez más, la opinión que el potencial turista pueda llegar a formarse de la modalidad de alojamiento resultará equívoca. Sólo si se acompaña de una descripción detallada del alojamiento, ilustrada con imágenes, este concepto será lo más ajustado posible a la realidad.

En lo referente a hoteles rurales, el problema no es tan patente. El vocablo hotel fue incorporado al español al mismo tiempo que a otros idiomas, y pertenece a la terminología turística comúnmente aceptada y usada.

Con las traducciones al inglés de términos que designan alojamientos rurales, el problema es el mismo que con el francés. Así, en la traducción de la tipología de casas rurales que no se alquilan completas, o casas rurales compartidas, se emplean diferentes expresiones que no suelen revelar las características de esta clase de alojamiento. Así, por ejemplo, tenemos el caso 
de guesthouse, que en inglés designa los alojamientos hoteleros que alquilan habitaciones con derecho a baño. Consecuentemente la traducción no reproduce el concepto al que hace referencia el término en español, debido a que la casa rural, por lo general, se comparte con los propietarios de ésta y no con otros posibles turistas. Además no es un establecimiento de alojamiento hotelero.

Algo parecido ocurre con el uso de la expresión to rent a shared house, que en el Reino Unido se refiere a casas que se alquilan para compartir entre un grupo de personas (como, por ejemplo, estudiantes), pero no necesariamente con finalidades turísticas, ni compartiéndola con los propietarios de ésta.

Encontramos otro ejemplo en rural house rooms, expresión a todas luces incorrecta, puesto que el alquiler de casas compartidas tiene más finalidades que la simple ocupación de habitaciones, tales como la convivencia con la familia arrendadora y la participación en las tareas típicas y los trabajos del medio rural, definición que obedece fundamentalmente al concepto de agroturismo.

También se acude, para la traducción de casa rural compartida, al uso de Bed \& Breakfast (B\&B). Estos establecimientos forman una cadena de alojamientos en casas particulares, repartidos por todo el país, en los que se ofrece la posibilidad de alquilar una habitación con derecho a desayuno (similar, por tanto, a casa de huéspedes). En este supuesto, aunque se comparte el alojamiento con los propietarios, falta la convivencia con estos y la finalidad exclusivamente turística.

En algunas traducciones encontramos la expresión rural apartment para hacer referencia a un conjunto arquitectónico global, situado en el medio rural, con alquiler de diferentes viviendas. Pero este término en nada obedece a la idea generalizada de apartamentos, porque estos están integrados en el mismo edificio, con la misma entrada, y suelen contar con un solo dormitorio. La expresión es aún menos adecuada para traducir el término "casa rural compartida".

Un caso parecido es el del vocablo bungalow, modelo de construcción consistente en una casa de una sola planta, que no tiene por qué estar situada en el medio rural, ni compartirse con los propietarios de ésta.

En estos dos últimos supuestos, los términos de la traducción no recogen la convivencia con la familia arrendadora, requisito de las casas rurales compartidas, además de ni siquiera existir en el Reino Unido o en países anglófonos el alojamiento denominado rural apartment.

Para la modalidad de casas rurales que se alquilan completas (es decir, que no se comparten con los propietarios), los términos usados en las traducciones también son variados y no exentos de polémica. Así, las expresiones rent a whole house y full house son utilizadas indistintamente. La segunda expresión, más incorrecta que la primera, incorpora el adjetivo full, que alude más al equipamiento completo con que cuenta la casa que a la oferta en 
alquiler de la totalidad del inmueble. Sin embargo, la idea de totalidad sí se consigue con el adjetivo whole. Aunque curiosamente consigue el efecto comunicativo, lo hace al precio de una desviación gramatical. Se ha producido un proceso de especialización léxica y/o idiomatización: ambos denotan lo mismo, pero "full" se refiere a la pluralidad del contenido (como en "full board", donde alude a las distintas comidas del día), mientras que "whole" alude a la singularidad del continente.

Por otra parte, cottages es un vocablo al que se recurre con demasiada frecuencia en las traducciones, por tratarse de un alojamiento situado en el campo. No obstante, este tipo de alojamiento tiene unas características arquitectónicas específicas que en casi nada coincidirán con las de las diferentes clases de casas rurales repartidas por toda la geografía española. Por ello, la traducción deberá ser completada con la descripción del alojamiento.

El término farmbouse presenta la misma problemática que la de su homólogo francés ferme, es decir, el concepto de granja como casa situada en el campo con animales. No todas las casas que se comercializan enteras tienen dependencias con animales. Quizá sería más correcto el uso de cottage para casas que no tienen animales y farm cottage para los supuestos en los que en el alojamiento, además de los servicios típicos, también haya animales de granja.

Por último, en algunas traducciones se recurre al término flat, cuando dicha denominación se refiere al modelo de bloque de pisos, con un carácter claramente urbano.

Problemas similares se observan en las traducciones de alojamientos con características especiales. Unas, con un uso inadecuado de vocablos, como puede ser shack para traducir cabaña de madera, término que posee claras connotaciones negativas (chabola, choza). ¿Cómo conseguir que un potencial turista de habla inglesa elija alojarse en una cabaña de madera si el término usado en la traducción es shack? Sería más correcta la expresión log cabin en lugar de la anterior, que denota abandono, suciedad y otras connotaciones negativas.

En otras traducciones, aparece de forma indiscriminada rural hostel o inn para designar por igual a albergues o granjas-escuela. La primera observación es que no se trata de tipologías rurales iguales, y la segunda, que sus finalidades no son las mismas, pues la del albergue es el alojamiento, y la de la granja-escuela es la enseñanza. Por ello, para denominar albergue debemos tomar el término inglés youth hostel.

En oposición a lo expuesto hasta ahora, la expresión cave house está correctamente empleada para la traducción de la modalidad de las casas-cueva que existen en Andalucía, definidas como viviendas trogloditas, excavadas en zonas rocosas.

En definitiva, la traducción a lenguas como el francés y el inglés de los términos que designan los diferentes tipos de alojamiento rural es, en muchos 
casos, poco acertada y no contribuye a que el turista extranjero se forme una idea correcta de las características del tipo de alojamiento sobre el que recibe información, y contribuyen, por el contrario, a la confusión. Esto, por otra parte, puede redundar en una mala percepción y una pobre imagen del turismo en la región o país, y tener consecuencias económicas.

\section{CONCLUSIONES}

En las secciones anteriores, se han revisado tanto el concepto y las características del turismo rural en España como los problemas derivados de la traducción de la terminología característica de este tipo de turismo. De los ejemplos presentados pueden extraerse las siguientes conclusiones.

En primer lugar, con respecto a la traducción de la tipología de alojamientos, es necesario el empleo de términos y expresiones que transmitan un mensaje lo más ajustado posible al concepto del alojamiento que se oferta. Se evitarán, en la medida de lo posible, las traducciones literales y el uso de términos procedentes de países que cuentan con modalidades diferentes de alojamiento a las españolas, con distintos servicios y ubicación.

Además, las traducciones deben ser lo más completas posibles, con descripciones detalladas de las características del alojamiento. No sólo se hará hincapié en la parte comercial o promocional del alojamiento, sino que se atenderá por igual o incluso en mayor medida a la información descriptiva complementaria, que será la que ayudará al turista extranjero a conocer las principales características del alojamiento y su entorno.

También se evitará omitir información en las traducciones, error en el que se incurre en la publicidad y comercialización de alojamientos a través de webs que disponen de información en varios idiomas.

Por último, es aconsejable cuidar los términos empleados y no acudir frecuentemente a la literalidad, para no conseguir el efecto contrario al que se quiere transmitir.

\section{BIBLIOGRAFÍA}

DahdÁ, Jorge (2005): Publicidad turística. México D. F., Editorial Trillas. FuENTES LuQUe, AdRIÁN (2005): "La traducción de textos de promoción turística institucional" en Fuentes Luque, A. (ed.): La traducción en el sector turístico. Granada, Atrio 